Abstract 88 Table 1 Performance statistics for clinical classification criteria-based algorithms for identifying sle in medical record data

\begin{tabular}{|c|c|c|c|c|c|c|c|c|}
\hline $\begin{array}{c}\text { Algorithm } \\
\text { Criteria }\end{array}$ & $\begin{array}{c}\text { True } \\
\text { Positive }\end{array}$ & $\begin{array}{c}\text { False } \\
\text { Positive }\end{array}$ & $\begin{array}{c}\text { True } \\
\text { Negative }\end{array}$ & $\begin{array}{c}\text { False } \\
\text { Negative }\end{array}$ & Sensitivity & Specificity & $\begin{array}{c}\text { Positive } \\
\text { Predictive } \\
\text { Value }\end{array}$ & $\begin{array}{c}\text { Negative } \\
\text { Predictive } \\
\text { Value }\end{array}$ \\
\hline ACR & $\begin{array}{r}323 / 472 \\
(68 \%) \\
\end{array}$ & $\begin{array}{r}6 / 128 \\
(5 \%) \\
\end{array}$ & $\begin{array}{r}122 / 128 \\
(95 \%)\end{array}$ & $\begin{array}{r}149 / 472 \\
(32 \%)\end{array}$ & $68 \%$ & $95 \%$ & $98 \%$ & $45 \%$ \\
\hline SLICC & $\begin{array}{r}369 / 472 \\
(78 \%)\end{array}$ & $\begin{array}{r}5 / 128 \\
(4 \%)\end{array}$ & $\begin{array}{r}123 / 128 \\
(96 \%)\end{array}$ & $\begin{array}{r}103 / 472 \\
(22 \%)\end{array}$ & $69 \%$ & $98 \%$ & $99 \%$ & $55 \%$ \\
\hline $\begin{array}{l}\text { proposed } \\
\text { EULAR/ACR }\end{array}$ & $\begin{array}{r}272 / 472 \\
(58 \%)\end{array}$ & $\begin{array}{r}5 / 128 \\
(4 \%)\end{array}$ & $\begin{array}{r}123 / 128 \\
(96 \%)\end{array}$ & $\begin{array}{r}200 / 472 \\
(42 \%)\end{array}$ & $52 \%$ & $96 \%$ & $98 \%$ & $35 \%$ \\
\hline
\end{tabular}

all three algorithms likely reflects undetected cases of SLE resulting from low detection of clinical and laboratory criteria (such as arthralgia and ANA tests) that are not consistently documented in structured data in the medical record. Use of structured data improves portability of the algorithms to other EHR datasets, but may have reduced the ability of the algorithms to detect important/highly weighted classification criteria that are documented primarily in free text notes. All three algorithms may improve through use of natural language processing (NLP) of physician notes for criteria that were difficult to detect using only diagnosis codes and labs, but may reduce portability as a result of the customization required for NLP to be effective.

Funding Source(s): National Institute of Arthritis and Musculoskeletal and Skin Diseases (R21 AR072263) and NHGRI U01HG006388

89 THE DIALATATION OF MAIN PULMONARY ARTERIAL
MEASURED BY CHEST MULTISLICE COMPUTED
TEMOGRAPHY PREDICT POOR LONG-TERM OUTCOME
IN CONNECTIVE TISSUE DISEASE ASSOCIATED
PULMONARY ARTERIAL HYPERTENSION

Xiaodi Li, Chunfang Zhang, Xiaoxuan Sun, Xiaoman Yang, Qiang Wang, Yinsu Zhu, Miaojia Zhang. The first affilicated hospital of Nanjing Medical University

\subsection{6/lupus-2019-Ism.89}

Background Pulmonary arterial dilatation is a common manifestation of chest multislice computed temography (MSCT) in patients with pulmonary arterial hypertension (PAH). The exact clinical significance of these phenomena has not been clarified in connective tissue disease (CTD) associated PAH. We want to observe whether the dilatation of pulmonary aterial was associated with poor outcome in patients with CTD-PAH.

Abstract 89 Table 1 Baseline demographic and clinical characteristics of survivors and non-survivors with 140 CTD-PAH

\begin{tabular}{|c|c|c|c|c|}
\hline & All Patients & Survivors & non-Survivors & $P$ value \\
\hline Subjects,n & 140 & $104(74 \%)$ & $36(36 \%)$ & --- \\
\hline Female,n & $132(94 \%)$ & $100(96 \%)$ & $32(89 \%)$ & 0.1055 \\
\hline Age,years & $44.32 \pm 16.11$ & $43.08 \pm 1.56$ & $47.92 \pm 2.15$ & 0.1234 \\
\hline $\begin{array}{l}\text { Underlying CTD } \\
\text { SLE,n } \\
\text { pSS,n } \\
\text { SSc,n } \\
\text { Overlap Syndrome,n } \\
\text { UCTD,n } \\
\text { MCTD,n } \\
\text { RA,n } \\
\text { DM,n }\end{array}$ & $\begin{array}{c}60(43 \%) \\
27(19 \%) \\
17(12 \%) \\
16(11 \%) \\
9(6 \%) \\
6(4 \%) \\
4(3 \%) \\
1(1 \%)\end{array}$ & $\begin{array}{c}45(43 \%) \\
22(21 \%) \\
9(9 \%) \\
12(12 \%) \\
7(7 \%) \\
5(5 \%) \\
3(3 \%) \\
1(1 \%)\end{array}$ & $\begin{array}{c}15(42 \%) \\
5(14 \%) \\
8(22 \%) \\
4(11 \%) \\
2(6 \%) \\
1(3 \%) \\
1(3 \%) \\
0\end{array}$ & $\begin{array}{l}0.8670 \\
0.3410 \\
\mathbf{0 . 0 3 1 7} \\
0.9446 \\
0.8043 \\
0.6042 \\
0.9735 \\
0.5549\end{array}$ \\
\hline Duration of CTD,months & $72.10 \pm 7.66$ & $64.68 \pm 8.43$ & $91.65 \pm 16.63$ & 0.0640 \\
\hline Duration of $\mathrm{PAH}$,months & $10.83 \pm 1.92$ & $10.16 \pm 2.24$ & $12.77 \pm 3.73$ & 0.0524 \\
\hline $\begin{array}{l}\text { WHO FC } \\
\text { I-II,n } \\
\text { III-IV,n }\end{array}$ & $\begin{array}{l}63(45 \%) \\
77(55 \%)\end{array}$ & $\begin{array}{l}34(33 \%) \\
70(67 \%)\end{array}$ & $\begin{array}{c}7(19 \%) \\
29(81 \%)\end{array}$ & $\begin{array}{c}<0.0001 \\
--\end{array}$ \\
\hline 6MWD,m & $359.90 \pm 21.81$ & $385.80 \pm 19.62$ & $278 \pm 57.16$ & 0.0239 \\
\hline NT-proBNP,ng/l & $2787 \pm 538.30$ & $1628 \pm 35.56$ & $6231 \pm 1842$ & $<0.0001$ \\
\hline PASP,mmHg & $69.24 \pm 1.59$ & $67.24 \pm 1.81$ & $74.49 \pm 3.21$ & 0.0427 \\
\hline $\begin{array}{l}\text { MPA diameter,mm } \\
\text { RPA diameter,mm } \\
\text { LPA diameter,mm } \\
\text { AAo diameter,mm } \\
\text { DAo diameter,mm } \\
\text { MPA/AAo } \\
\text { MPA/DAo }\end{array}$ & $\begin{array}{c}35.52 \pm 0.43 \\
23.63 \pm 0.31 \\
18.95 \pm 0.30 \\
30.60 \pm 0.42 \\
22.33 \pm 0.27 \\
1.18 \pm 0.02 \\
1.62 \pm 0.02\end{array}$ & $\begin{array}{c}34.72 \pm 0.48 \\
23.23 \pm 0.36 \\
18.46 \pm 0.34 \\
30.25 \pm 0.49 \\
22.05 \pm 0.31 \\
1.18 \pm 0.02 \\
1.61 \pm 0.03\end{array}$ & $\begin{array}{c}37.84 \pm 0.86 \\
24.76 \pm 0.60 \\
20.36 \pm 0.57 \\
31.63 \pm 0.84 \\
23.14 \pm 0.55 \\
1.20 \pm 0.03 \\
1.64 \pm 0.05\end{array}$ & $\begin{array}{l}\mathbf{0 . 0 0 1 2} \\
\mathbf{0 . 0 2 6 8} \\
\mathbf{0 . 0 0 6 5} \\
0.1492 \\
0.0805 \\
0.5656 \\
0.7047\end{array}$ \\
\hline
\end{tabular}




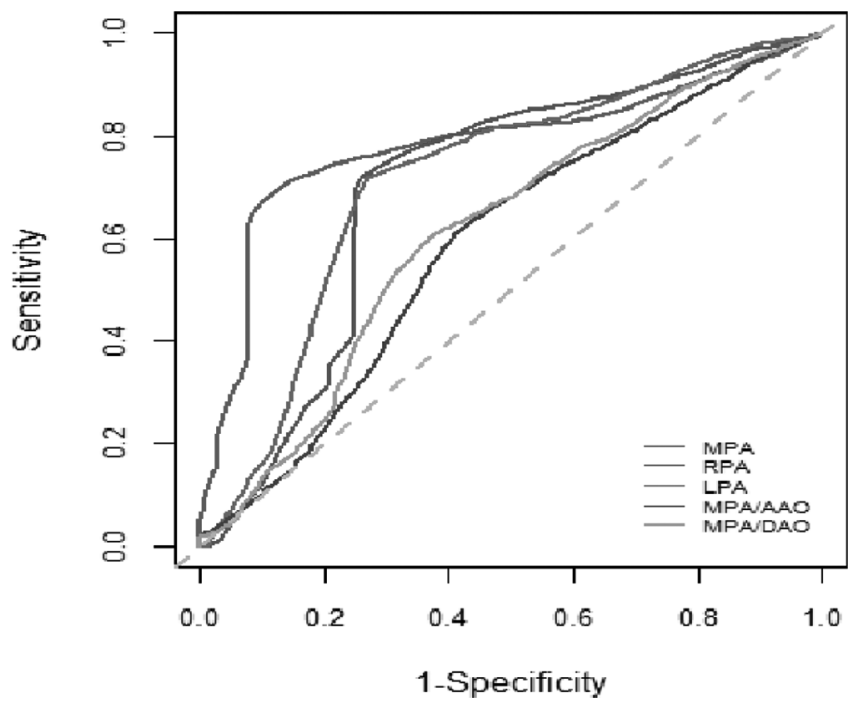

Abstract 89 Figure 2 Time-dependent ROC curve showing the 10years prognostic value of MSCT parameters. These results suggest that MPA diameter, PRA diameter and LPA diameter may have prognositic value in CTD-PAH patients

$$
\text { Srata }+ \text { MPA }<37.70+\cdot \text { MPA }>=37.70
$$
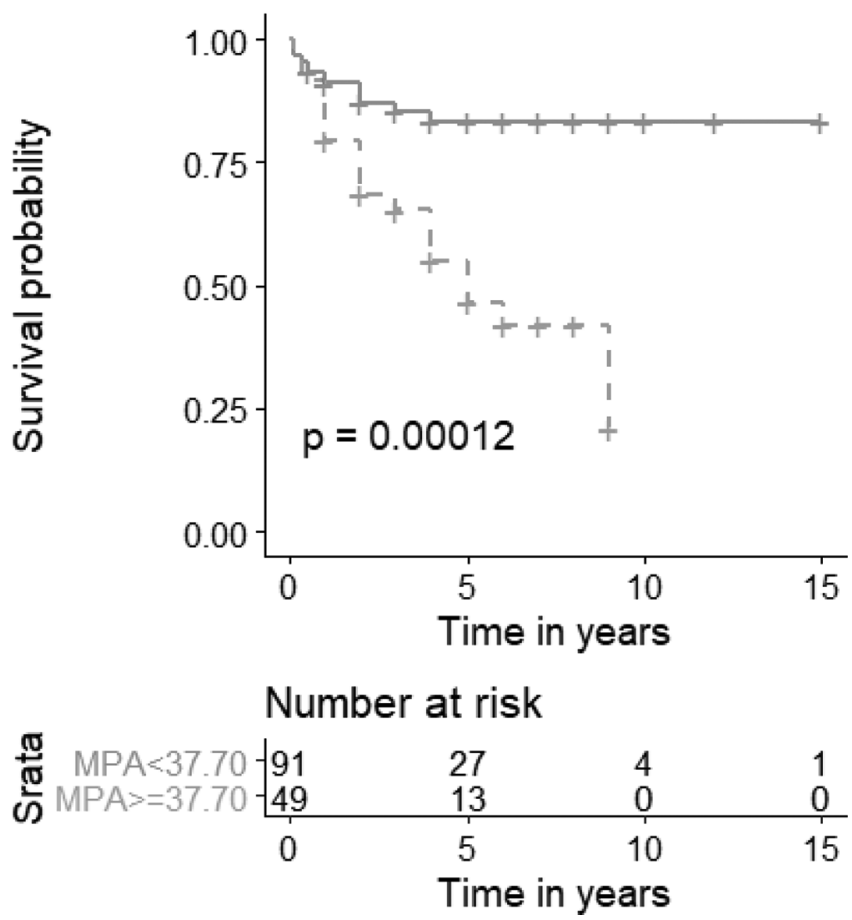

Abstract 89 Figure 3 Kaplan-Meier analysis of the long-term prognosis based on MSCT parameters. (A) Kaplan-Meier analysis showed significant differences in the prognosis between the patients with MPA diameter $<37.70$ $\mathrm{mm}$ and those with MPA diameter $\geq 37.70 \mathrm{~mm}$ (Long-rank test $\mathrm{p}=0.00012$ ).

Methods We retrospectively investigated 140 CTD-PAH patients diagnosed by echocardiography during 2010 and 2018 at the first affiliated hospital of Nanjing Medical University. Digital scout chest MSCT information was obtained. Main pulmonary arterial (MPA), right pulmonary arterial (RPA) branch, left pulmonary arterial (IPA) branch, ascending aorta (AAO) and descending aorta (DAO) diameters were
Srata + LPA $<20.20+\cdot$ LPA $>=20.20$

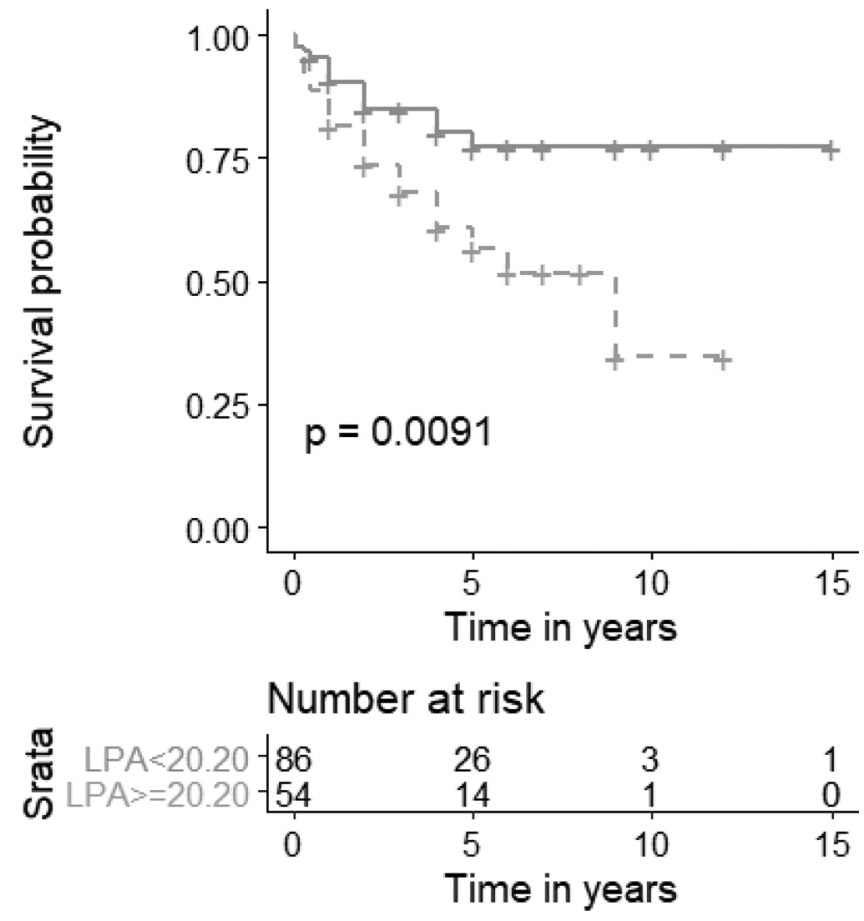

Abstract 89 Figure 3 (B) Kaplan-Meier analysis showed significant differences in the prognosis between the patients with LPA diameter $<20.20 \mathrm{~mm}$ and those with LPA diameter $\geq 20.20 \mathrm{~mm}$ (Long-rank test $\mathrm{p}=0.0091$ ).

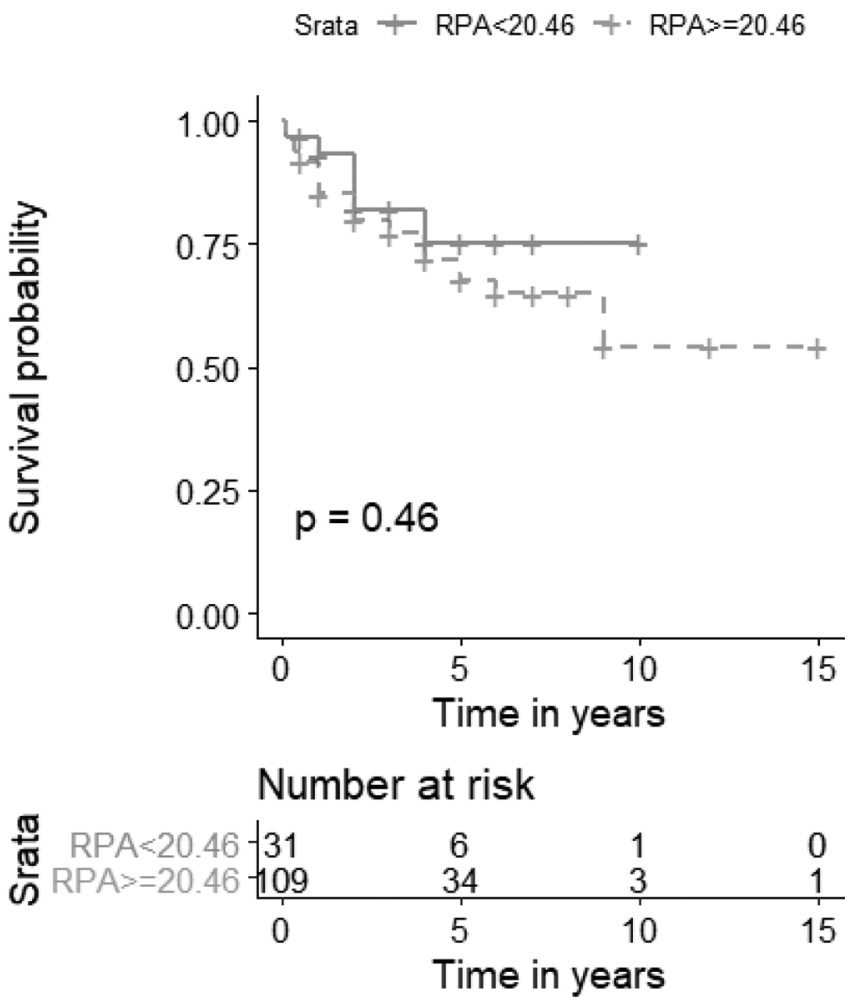

Abstract 89 Figure 3 (C) Kaplan-Meier analysis showed no significant differences in the prognosis between the patients with RPA diameter $<20.46 \mathrm{~mm}$ and those with RPA diameter $\geq 20.46 \mathrm{~mm}$ (Long-rank test $\mathrm{p}=0.46)$. 
Abstract 89 Table 2 Area under the curve

\begin{tabular}{ccccccc}
\hline Test result & Area & P value & Cut-off & Hazard & \multicolumn{2}{c}{ Asymptotic 95\% confidence interval } \\
\cline { 6 - 7 } variables & & & Value & ratio & Lower bound & Upper bound \\
\hline MPA diameter & 0.81 & 0.003 & 37.70 & 1.13 & 1.05 & 1.22 \\
RPA diameter & 0.70 & 0.015 & 20.46 & 1.15 & 0.10 & 1.21 \\
LPA diameter & 0.72 & 0.020 & 20.20 & 1.10 & 1.04 & 1.27 \\
MPA/AAo & 0.59 & 0.455 & 1.12 & 3.95 & 0.58 & 26.94 \\
MPA/DAo & 0.62 & 0.378 & 1.61 & 3.68 & 0.88 & 15.46 \\
\hline
\end{tabular}

Abstract 89 Table 3 Univariate and multivariate analyses for mortality

\begin{tabular}{ccccc}
\hline Prognosis & \multicolumn{2}{c}{ Univariate } & \multicolumn{3}{c}{ Multivariate } \\
factor & Hazard ratio $(95 \% \mathrm{CI})$ & P value & Hazard ratio(95\% CI) & P value \\
\hline Male & & $\mathbf{0 . 0 5 1}$ & $0.26(0.09-0.77)$ & $\mathbf{0 . 0 1 5}$ \\
SLE & & 0.477 & & \\
SSc & & $\mathbf{0 . 0 6 6}$ & & \\
Mild ILD & & 0.261 & & $\mathbf{0 . 0 2 0}$ \\
Pericardial Effusion & & $\mathbf{0 . 1 5 7}$ & $0.40(0.19-0.89)$ & $\mathbf{0 . 0 1 9}$ \\
MPA d $\geq 37.70 \mathrm{~mm}$ & $0.29(0.15-0.58)$ & $\mathbf{0 . 0 0 0}$ & $0.28(0.14-0.58)$ & \\
LPA d $\geq 20.20 \mathrm{~mm}$ & $0.43(0.22-0.84)$ & $\mathbf{0 . 0 1 1}$ & & $\mathbf{0 . 0 0 1}$ \\
WHO FC III-IV & $0.25(0.11-0.56)$ & $\mathbf{0 . 0 0 1}$ & $3.74(1.61-8.71)$ & \\
GCs Treatment & & 0.623 & & \\
IM Treatment & & 0.402 & & \\
PAH Targeted Drug treatment & & 0.883 & & \\
\hline
\end{tabular}

In multivariate analysis, MPA diameter $\geq 37.70 \mathrm{~mm}$, pericardial effusion, male and WHO functional class III-IV were independent predictors of poor prognosis in patients with CTD-PAH.

measured by professional radiologist. The ratio of MPA/AAO, MPA/DAO were also caiculated.

Results During the observational period of $3.44 \pm 0.23$ years, 2 patients were died of serious infection, 1 patients was died of renal failuer and 33 patients were died of heart faliure. The time dependent receiver operating characteristic (ROC) curve suggested that MPA, PRA and LPA diameter may have the 10 year prognositic value in CTD-PAH patients, the corresponding cut-off values were MPA>37.70 mm, RPA $>20.46 \mathrm{~mm}$ and LPA $>20.20 \mathrm{~mm}$. Kaplan-Meier analysis showed significant difference in the long-term prognosis between patients with MPA diameter $<37.70 \mathrm{~mm}$ and MPA diameter $37.70 \mathrm{~mm}$ (Long-rank test $\mathrm{p}=0.00012$ ) and between patients with LPA diameter $<20.20 \mathrm{~mm}$ and LPA diameter $20.20 \mathrm{~mm}$ (Long-rank test $\mathrm{p}=0.0091$ ). The multivariate analyses suggested that MPA $37.70 \mathrm{~mm}$ was the independent risk factor of poor outcome of CTD-PAH patients (HR: 0.28; 95\% CI: 0.14-0.58 $\mathrm{p}=0.01)$.

Conclusions Main pulmonary arterial dilatation measured by MSCT was associated with the poor prognosis in patients with CTD-PAH.

Funding Source(s): None

\section{SOCIOECONOMIC DISPARITIES IN LUPUS NEPHRITIS: FINDINGS FROM THE SOUTHERN CALIFORNIA LUPUS REGISTRY}

${ }^{1}$ Arezoo Haghshenas*, ${ }^{2}$ Kristal Choi, ${ }^{3}$ Phildrich The, ${ }^{2}$ Abigail Benitez, ${ }^{2}$ Lorena M Salto, ${ }^{2}$ Karina Torralba, ${ }^{2}$ Vaneet K Sandhu. ${ }^{1}$ Loma Linda University Health; ${ }^{2}$ Loma Linda University; ${ }^{3} U C$ Riverside

10.1136/lupus-2019-Ism.90
Background Systemic Lupus Erythematous (SLE) is a chronic multi-systemic autoimmune disease. Despite therapeutic advancements, lupus nephritis (LN), which occurs in $25 \%-75 \%$ of individuals with SLE, remains a major cause of mortality. Prior studies have demonstrated poor outcomes in SLE occurring more frequently in both ethnic minority groups as well as in those with low socioeconomic status (SES). Factors attributing to greater mortality rates in these populations include patient resistance to treatment, compliance, low SES and genetics.

Methods Subjects were selected from SCOLR, a prospective registry enrolling all-comers with SLE. Inclusion criteria were LN subjects with available biopsy report. Subjects with renal transplant and unknown LN class were excluded. Data collected included demographics, insurance information, clinical and serologic variables specifically to establish an SLE disease activity index (SLEDAI). Subjects were categorized by self-reported ethnicity: White Hispanic, White non-Hispanic, Black, and Asian/ Pacific Islander. Further sub-analysis was carried out on individuals with public vs. private insurance. Insurance and ethnicity were used as surrogates for socioeconomic status and descriptive statistical analyses were calculated to determine if observed differences were statistically significant.

Results One hundred and sixty-two medical charts were reviewed. Of those, $50 \%$ of subjects were White Hispanic, $31.8 \%$ White non-Hispanic, $8.7 \%$ Black, and 6.6\% Asian/ Pacific Islander. After adjusting for age, sex, and BMI, public insurance was independently associated with the prevalence of LN ( $p=0.038)$.

We performed a subgroup analysis of the $35 \mathrm{LN}$ subjects to observe the association between SES with treatment outcomes. Proteinuria was higher in subjects with public insurance at baseline and this difference was statistically significant 